JURNAL EKONOMI

EFEKTIF
ISSN : $2622-8882$, E-ISSN : 2622-9935

Jurnal Ekonomi Efektif, Vol. 2, No. 1, Oktober 2019

@Prodi Manajemen Fakultas Ekonomi Universitas

Pamulang

\title{
ANALISIS PENGARUH BUDAYA ORGANISASI DAN INSENTIF TERHADAP MOTIVASI KERJA YANG BERDAMPAK PADA PRODUKTIVITAS KARYAWAN PADA PT OPTIMA MEDIA SINERGI
}

\author{
Aidil Amin Effendy \\ dosen00967@unpam.ac.id
}

\begin{abstract}
ABSTRAK
Tujuan dari penelitian ini adalah untuk mengetahui pengaruh Budaya Organisasi terhadap Motivasi Kerja, pengaruh Insentif terhadap Motivasi Kerja, pengaruh Budaya Organisasi dan Insentif secara simultan terhadap Motivasi Kerja dan mengetahui pengaruh Motivasi Kerja terhadap Produktivitas Karyawan pada PT. Optima Media Sinergi. Metode penelitian yang dipergunakan dalam penelitian ini adalah metode assosiatif kuantitatif dan pengumpulan data dengan observasi dan penyebaran kuesioner. Sampel dalam penelitian ini sebanyak 52 orang karyawan. Metode analisis data dengan uji validitas, uji reliabilitas, uji asumsi klasik, persamaan regresi linier berganda, korelasi berganda, koefisien determinasi dan uji hipotesis. Hasil penelitian menunjukkan korelasi berganda sebesar $r=0,543$ yang berarti hubungan antara budaya organisasi dan insentif terhadap motivasi kerja karyawan pada PT Optima Media Sinergi berada pada kategori sedang. Nilai koefisien determinasi (KD) tersebut diperoleh sebesar 29,50\%. Hal ini menunjukan bahwa besarnya kontribusi variabel budaya organisasi dan insentif terhadap motivasi kerja karyawan sebesar 29,50\%, sedangkan selebihnya sebesar $70.50 \%$ dipengaruhi faktor-faktor lain. Adapun hasil uji $\mathrm{F}$ dapat diperoleh nilai $\mathrm{f}_{\text {hitung }}>\mathrm{f}_{\text {tabel }}$ yaitu $10,254>3,18$ dan nilai sig $0,000<0,005$. "Maka, Budaya Organisasi $\left(\mathrm{x}_{1}\right)$ dan Insentif $\left(\mathrm{x}_{2}\right)$ memiliki pengaruh yang signifikan terhadap Motivasi Kerja $(\mathrm{y}) "$ ".
\end{abstract}

\section{Kata Kunci : Budaya organisasi, Insentif, Motivasi kerja dan Produktivitas}

\section{ABSTRACT}

The purpose of this study was to determine the effect of Organizational Culture on Work Motivation, the effect of Incentives on Work Motivation, the influence of Organizational Culture and Incentives simultaneously on Work Motivation and determine the effect of Work Motivation on Employee Productivity at PT. Optima Media Synergy. The research method used in this study is a quantitative associative method and data collection by observation and questionnaire distribution. The sample in this study were 52 employees. Methods of data analysis using validity, reliability testing, classic assumption tests, multiple linear regression equations, multiple correlations, coefficient of determination and hypothesis testing. The results showed a multiple correlation of $r=0.543$ which means the relationship between organizational culture and incentives for employee work motivation at PT Optima Media Sinergi are in the medium category. The coefficient of determination (KD) was obtained by $29.50 \%$. This shows that the magnitude of the contribution of organizational culture variables and incentives to employee work motivation by $29.50 \%$, while the remaining $70.50 \%$ is 
influenced by other factors. The $F$ test results can be obtained the value of $f$ count $>f$ table is $10.254>3.18$ and sig value $0.000<0.005$. "Thus, Organizational Culture (x1) and Incentives (x2) have a significant influence on Work Motivation (y)".

\section{Keywords: Organizational Culture, Incentives, Work Motivation and Productivity}

\section{PENDAHULUAN}

\section{A. Latar Belakang}

PT. Optima Media Sinergi sebagai perusahaan digital marketing yaitu perusahaan yang melayani konsumen dalam pembuatan website, blog dan pemasaran melalui media online merupakan perusahaan yang harus mengembangkan produknya dan meningkatkan penjualannya dengan cara memotivasi karyawan agar produktivitasnya meningkat. Disamping membangun kompetensi di bidang jasa, perusahaan juga memberikan perhatian khusus kepada pembinaan SDM dalam melayani customer, maupun dalam teknologi yang prima.

Dalam meningkatkan motivasi kerja, terdapat permasalahan yang terjadi diantaranya yaitu mengenai Budaya Organisasi yang kurang baik seperti absensi keterlambatan yang cukup signifikan sehingga dapat mengkibatkan kerugian dalam penyelesaian pekerjaan dan penurunan kinerja. Maka hal itu tidak sesuai dengan budaya organisasi yang ada di PT. Optima Media Sinergi, yaitu budaya yang berdasarkan nilai-nilai kewirausahaan, etika, kerjasama, dinamis, dan komitmen, oleh karena itu hal tersebut mengindikasikan bahwa penerapan budaya organisasi di PT. Optima Media Sinergi belum berjalan dengan baik.

Insentif yang diberikan oleh PT. Optima Media Sinergi diharapkan dapat memberikan energi positif untuk karyawan yang bekerja, dan dapat mempengaruhi perilaku serta sikap kerja karyawan sesuai dengan pencapaian target yang di tetapkan oleh PT. Optima Media Sinergi. Namun insentif yang diberikan tidak sesuai dengan skala pekerjaan pegawai, dan sistem pemberian insentif yang tidak sesuai dengan harapan karyawan.

Motivasi karyawan dapat dipengaruhi faktor minat gaji yang diterima, kebutuhan akan rasa aman, hubungan antar personal dan kesempatan untuk bekerja. Dengan adanya motivasi dapat merangsang karyawan untuk lebih menggerakan tenaga dan pikiran dalam merealisasikan tujuan perusahaan. Apabila kebutuhan akan hal ini terpenuhi maka akan timbul kepuasan dan kelancaran terhadap peningkatan produktivitas kerja karyawan.

Produktivitas kerja dapat dicapai apabila didukung oleh karyawan yang mempunyai motivasi yang tinggi dan lingkungan kerja yang kondusif untuk melaksanakan tugas dan kewajibannya. Maka, motivasi tersebut mempengaruhi tingkat produktivitas kerja karyawan.

Oleh karena itu salah satu solusi untuk meningkatkan produktivitas karyawan adalah dengan memberikan insentif kepada karyawan agar dapat memotivasi sehingga karyawan lebih meningkatkan lagi produktivitasnya, ketika kinerjanya meningkat dan perusahaan pun akan mampu menghasilkan produk dengan harga yang kompetitif. Berangkat dari latar belakang masalah diatas maka penenilit mengambil judul "Analisis Pengaruh Budaya Organisasi dan Insentif terhadap Motivasi Kerja yang berdampak pada Produktivitas Karyawan Pada PT. Optima Media Sinergi”.

\section{B. Rumusan Masalah}

1. Bagaimana pengaruh Budaya Organisasi terhadap Motivasi Kerja pada PT. Optima Media Sinergi?

2. Bagaimana pengaruh Insentif terhadap Motivasi Kerja pada PT. Optima Media Sinergi?

3. Bagaimana pengaruh Budaya Organisasi dan Insentif secara simultan terhadap Motivasi Kerja PT. Optima Media Sinergi? 
4. Bagaimana pengaruh Motivasi Kerja terhadap Produktivitas Karyawan pada PT. Optima Media Sinergi?

\section{Tujuan Penelitian}

1. Untuk mengetahui pengaruh Budaya Organisasi terhadap Motivasi Kerja pada PT. Optima Media Sinergi.

2. Untuk mengetahui pengaruh Insentif terhadap Motivasi Kerja pada PT. Optima Media Sinergi

3. Untuk mengetahui pengaruh Budaya Organisasi dan Insentif secara simultan terhadap Motivasi Kerja PT. Optima Media Sinergi

4. Untuk mengetahui pengaruh Motivasi Kerja terhadap Produktivitas Karyawan pada PT. Optima Media Sinergi

\section{Kerangka Pemikiran}

Analisis Pengaruh Budaya Organisasi dan Insentif terhadap Motivasi Kerja yang berdampak pada Produktivitas Karyawan Pada PT. Optima Media Sinergi

\section{E. Hipotesis Penelitian}

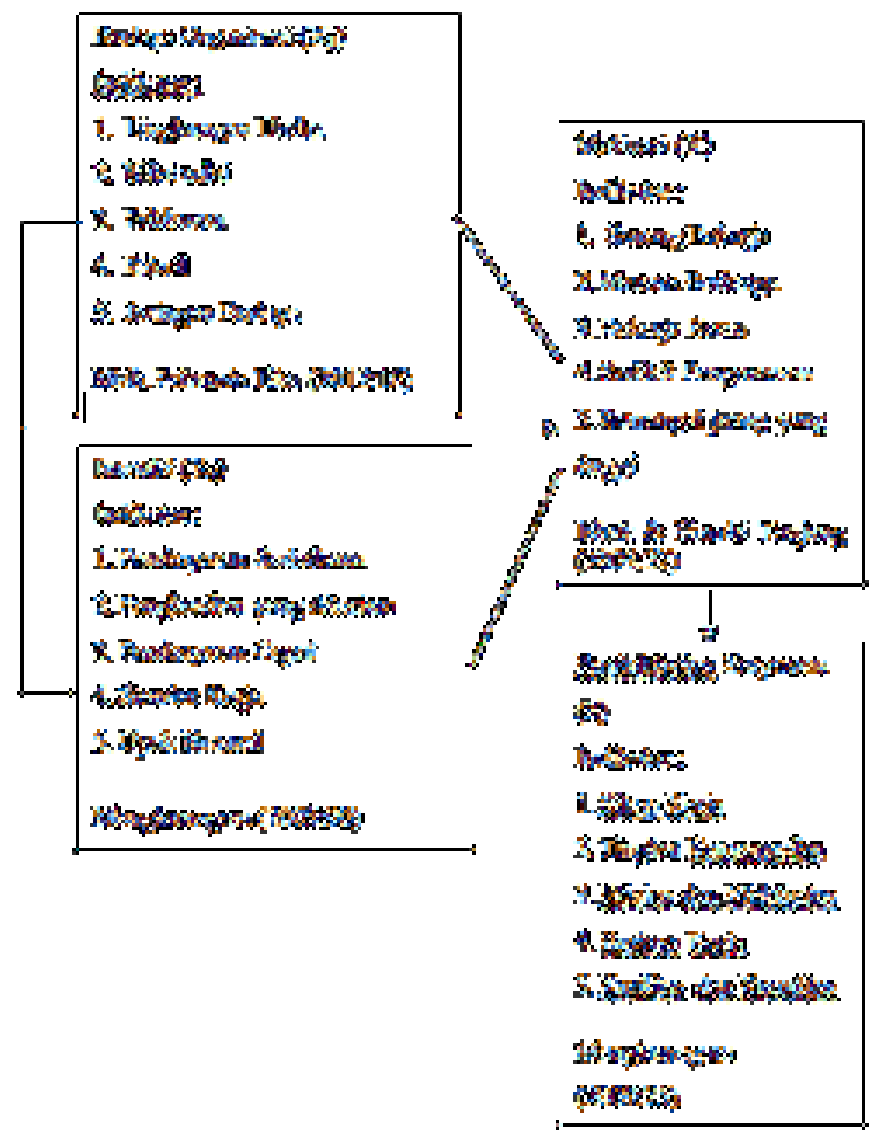

Gambar 1. Kerangka Pemikiran

Berdasarkan kerangka pemikiran di atas, maka diajukan suatu hipotesa penelitian, yaitu :

1. $\mathrm{H}_{01}=$ Tidak ada pengaruh insentif terhadap produktivitas kerja

$\mathrm{H}_{\mathrm{a} 1}=$ Ada pengaruh insentif terhadap produktivitas kerja

2. $\mathrm{H}_{\mathrm{o} 2}=$ Tidak ada pengaruh motivasi terhadap produktivitas kerja 
$\mathrm{H}_{\mathrm{a} 2}=$ Ada pengaruh motivasi terhadap produktivitas kerja

3. $\mathrm{H}_{03}=$ Tidak ada pengaruh insentif dan motivasi secara simultan terhadap produktivitas kerja.

4. $\mathrm{H}_{\mathrm{a} 3}=$ Ada pengaruh insentif dan motivasi secara simultan terhadap produktivitas kerja

5. $\mathrm{H}_{04}=$ Tidak ada pengaruh motivasi kerja terhadap produktivitas kerja Karyawan

$\mathrm{H}_{\mathrm{a} 4}=$ Ada pengaruh motivasi kerja terhadap produktivitas kerja

\section{TINJAUAN PUSTAKA}

\section{A. Budaya organisasi}

Robert G. Owens dalam bukunya Organizational Behavior in Education mengemukakan definisi budaya menurut Terrence dan Allan Kennedy, "Budaya adalah sustu sistem pembagian nilai dan kepercayaan yang berintegrasi dengan orang dalam suatu organisasi, struktur organisasi, dan sistem kontrol yang menghasilkan norma pelaku." (Moh. Pabunda Tika, 2012:2-3)

Menurut Ernest Dale dalam Akhmad Subkhi, (2013:3), organisasi adalah "Suatu proses perencanaan yang meliputi penyusunan, pengembangan, dan pemeliharaan suatu struktur atau pola hubungan kerja dari orang-orang dalam suatu kerja kelompok.

Budaya organisasi menurut Peter F. Duicker dalam buku Robert G. Owens, Organizational Behavior in Education adalah pokok penyelesaian masalah masalah eksternal dan internal yang pelaksanaannya dilakukan secara konsisten oleh suatu kelompok yang kemudian mewariskan kepada anggota anggota baru sebagai cara yang tepat untuk memahai, memikirkan, dan merasakan terhadap masalah-masalah terkait seperti diatas. (Moh. Pabunda Tika, 2012:4)

\section{B. Motivasi kerja}

Menurut Mangkunegara (2009:89) mengemukakan bahwa insentif adalah "Suatu penghargaan dalam bentuk uang yang diberikan oleh pihak pimpinan organisasi kepada karyawan agar mereka bekerja dengan motivasi yang tinggi dan berprestasi berprestasi yang tinggi dalam mencapai tujuan- tujuan organisasi, atau dengan kata lain insentif merupakan pemberian uang diluar gaji yang dilakukan oleh pihak organisasi sebagai pengakuan terhadap prestasi kerja dan kontribusi karyawan kepada organisasi."

Menurut Heru Tri (2010:154), mengemukakan bahwa "insentif merupakan imbalan yang ditambahkan terhadap upah atau gaji yang biasanya berkaitan secara langsung dengan prestasi kerja. Dan menurut Hasibuan (2009:183), insentif adalah daya perangsang yang diberikan kepada karyawan tertentu berdasarkan prestasi kerjanya agar karyawan terdorong meningkatkan produktivitas kerjanya."

\section{Motivasi}

Sperling dalam Mangkunegara (2009:93) mengemukakan bahwa motif didefinisikan sebagai "Suatu kecenderungan untuk beraktifitas, dimulai dari dorongan dalam diri dan diakhiri dengan penyesuaian diri yaitu untuk memuaskan motif." Encyclopedia dalam Hasibuan (2009:142) mengemukakan "Motivasi adalah suatu kecenderungan dalam diri seseorang yang dibangkitkan topangan dan mengarahkan tindak- tanduknya."

\section{Produktivitas}

Produktivitas adalah ukuran efisiensi produktif. Suatu perbandingan antara hasil keluaran dan masukan. Masukan sering dibatasi dengan tenaga kerja, sedangkan keluaran diukur dalam 
satuan fisik, bentuk, dan nilai (Edy Sutrisno,2011:99). Produktivitas kerja adalah hasil konkrit (produk) yang dihasilkan oleh individu atau kelompok selama satuan waktu tertentu dalam suatu proses kerja (Tjutju Yuniarsih dan Suwanto, 2008:156).

\section{METODE PENELITIAN}

\section{A. Tempat dan Waktu Penelitian}

Penelitian ini dilakukan di alamat Penelitian dilakukan di PT. Optima Media Sinergi yang beralamat di J1. Aria Putra, No.67, Serua Indah, Ciputat, Kota Tangerang Selatan, Banten. Waktu dan pelaksanaan penelitian mengumpulkan data dilakukan selama 6 (enam) bulan hingga tercukupi data dan informasi serta sampai pengolahan data untuk didapatkan hasil penelitian yang ada.

\section{B. Metode Penelitian}

Dalam penelitian yang dilakukan di PT. Optima Media Sinergi menggunakan metode yang bersifat assosiatif kuantitatif. Menurut Suryono (2010:9) penelitian kuantitatif adalah penelitian yang digunakan untuk menyelidiki, menemukan, meramalkan dan menjelaskan kualitas atau keistimewaan dari pengaruh sosial yag dapat dijelaskan, diukur atau digambarkan melalui pendekatan kuantitatif.

Menurut Sugiyono (2011:21) pendekatan asosiatif penelitian yang bertujuan untuk mengetahui dua variable atau lebih. Dalam penelitian ini maka akan dapat dibangun suatu teori yang dapat berfungsi untuk menjelaskan, meramalkan dan mengontrol suatu gejala.

\section{Populasi dan Sampel \\ 1. Populasi}

Populasi menurut Sugiyono (2009:90) adalah "Wilayah generalisasi yang terdiri dari obyek atau subyek yang menjadi kualitas dan karakteristik tertentu yang ditetapkan oleh peneliti untuk dipelajari dan kemudian ditarik kesimpulannya." Berdasarkan pada tempat penelitian yang telah ditetapkan, maka populasi yang dijadikan objek dalam penelitian ini adalah karyawan pada PT. Optima Media Sinergi yang berjumlah 52 responden.

\section{Sampel}

Sampel menurut Sugiyono (2009:96) adalah "Bagian dari populasi yang dipergunakan sebagai sumber data yang sebenarnya." Dengan kata lain, sampel merupakan bagian dari populasi. Pembagian jenis sampel yang diterapkan oleh Sugiyono (2009:96) "Ada berbagai macam. Diantaranya penulis menerapkan dalam penelitian dengan menggunakan sampel Jenuh, dimana teknik pengumpulan sampel bisa semua anggota populasi digunakan sebagai sampel." Hal ini sering dilakukan bila jumlah populasi dianggap kecil atau kurang dari 100 orang. Adapun sampel di penelitian ini yaitu 52 orang, sesuai jumlah populasi di perusahaan.

\section{Teknik Pengumpulan Data}

Adapun Teknik pengumpulan data dalam penelitian ini menggunakan beberapa Teknik sebagai berikut:

1. Observasi adalah salah satu metode penelitian yang dilakukan dengan cara mengamati secara langsung obyek penelitian yaitu PT. Optima Media Sinergi.

2. Studi Dokumentasi adalah pengumpulan data melalui dokumen-dokumen berupa laporan PT. Optima Media Sinergi dan data lain yang menunjang dalam penelitian ini. 
3. Daftar pertanyaan (Questionnaire) yang diberikan kepada pegawai PT. Optima Media Sinergi yang dijadikan sampel penelitian kemudian dari jawaban setiap pertanyaan tersebut ditentukan skornya dengan menggunakan skala likert. Menurut Sugiyono (2011:93) skala likert digunakan untuk mengukur sikap, pendapat, dan persepsi seseorang atau kelompok orang tentang fenomena "social".

\section{E. Sumber Data}

Menurut Sugiyono (2009:12) sumber data adalah segala sesuatu yang dapat memberikan informasi mengenai data berdasarkan sumbernya, data dibedakan menjadi dua, yaitu :

1. Data Primer

Data Primer merupakan data yang diperoleh langsung dari pegawai yang dijadikan sampel penelitian dari penyebaran.

2. Data Sekunder

Data sekunder merupakan data yang mendukung data primer yang diperoleh peneliti dari dokumen- dokumen di PT. Optima Media Sinergi.

\section{F. Metode Analisa Data}

Analisis data Analisis data yang digunakan dalam penelitian ini adalah uji validitas dan uji reliabilitas.

\section{Uji Validitas}

Pengujian validitas menggunakan rumus korelasi pearson product moment, dengan ketentuan jika hitung $r>$ tabel $r$, berarti instrumen valid.

\section{Uji Reliabilitas}

Pengujian reliabilitas dalam penelitian ini menggunakan nilai Alpha Coanbach dengan ketentuan jika Alpha Croanbach ( hitung $\mathrm{r}$ ) $>0,60$ berarti instrumen tersebut reliabel. Teknik analsis data antara lain uji asumsi klasik dan analisis regresi ganda. Uji asumsi klasik terdiri dari uji normalitas, uji multikolinearitas dan uji heteroskedastisitas.

\section{Uji Asumsi Klasik}

\section{a) Uji Normalitas}

Uji normalitas adalah pengujian tentang kenormalan distribusi data. Uji normalitas bisa dilakukan dengan dua cara yaitu dengan "Normal P-P Plot" dan "Tabel Kolmogorov Smirnov" yang paling umum digunakan adalah Normal P- P Plot. Pada normal P- P Plot prinsipnya normalitas dapat dideteksi dengan melihat penyebaran data (titik) pada sumbu diagonal grafik atau dengan melihat histogram dari residualnya. Jika data menyebar di sekitar garis diagonal dan mengikuti arah garis diagonal atau grafik histogramnya menunjukkan pola distribusi normal, maka model regresi memenuhi asumsi normalitas.

\section{b) Uji Multikolinearitas}

Uji Multikolinearitas dilakukan untuk mengetahui ada tidaknya kemiripan yang dimiliki oleh satu variabel independent dengan variabel independen yang lain dalam satu model. Pengujian multikolinearitas dalam penelitian ini menngunakan VIF (Variance Inflation Factor), dengan ketentuan jika nilai tolerance $>0,1$ dan nilai VIF $<10$, maka data tidak maka data tidak mengalami multikolinearitas.

\section{c) Uji Heterokedastisitas}

Pengujian ini untuk mengetahui apakah terjadi penyimpangan model karena gangguan variabel yang berbeda antar observasi ke observasi lain. Untuk mengetahui 
apakah terjadi heteroskedastisitas atau tidak, dapat dilihat pada gambar Scattreplot, jika pada gambar scatterplot tidak ada pola yang jelas serta titik-titik menyebar di atas dan dibawah angka 0 pada sumbu Y, maka tidak terjadi heterokedastisistas.

\section{Analisis Regresi berganda}

Teknik analisis regresi ganda dipergunakan untuk mengetahui Analisis Pengaruh Budaya Organisasi dan Insentif terhadap Motivasi Kerja yang berdampak pada Produktivitas Karyawan Pada PT. Optima Media Sinergi Dengan persamaan regresi $Y=a+b_{1} X_{1}+X_{2} b_{2}+X_{3} b_{3}$.

Teknik pengujian hipotesis menggunakan uji parsial dan uji simultan dengan teknik probabilitas, dengan cara membandingkan nilai probabilitas Sig dengan taraf signifikansi 0,05 . Jika nilai probabilitas sig $<0,05$ maka signifikan.

\section{Koefisien Korelasi}

Pengujian koefisien korelasi ini digunakan untuk mengetahui kekuatan hubungan antara korelasi kedua variabel dimana variabel lainnya yang dianggap berpengaruh dikendalikan atau dibuat tetap (sebagai variabel kontrol). Karena variabel yang diteliti adalah interval maka teknik statistik yang diguanakan adalah Pearson Correlation Product Moment (Sugiyono, 2013:216).

\section{Koefisien Determinasi}

Pengujian koefisien determinasi bertujuan untuk mengetahui besarnya pengaruh antar variabel. Nilai koefisien determinasi menunjukkan presentase variasi nilai variabel dependen yang dapat dijelaskan oleh persamaan regresi yang dihasilkan.

\section{Uji Hipotesis}

\section{1) Uji T}

Uji $\mathrm{t}$ digunakan untuk mengetahui hubungan masing-masing variabel independen secara individual terhadap variabel dependen. Untuk mengetahui ada tidaknya pengaruh masing- masing variable independen secara individual terhadap variabel dependen digunakan tingkat signifikasi 5\%. Jika probability t lebih besar dari 0,05 maka tidak ada pengaruh variabel independen terhadap variable dependen.

2) Uji F

Uji statistik F pada dasarnya menunjukkan apakah semua variabel bebas yang dimasukkan dalam model mempunyai pengaruh secara bersama- sama terhadap variabel dependen. Menurut Ghozali (2005:84) jika nilai probability F lebih besar dari 0,05 maka model regresi tidak dapat digunakan untuk memprediksi variabel dependen atau dengan kata lain variabel independen secara bersama- sama tidak berpengaruh terhadap variabel dependen.

\section{HASIL DAN PEMBAHASAN}

\section{A. Gambaran Umum Obyek Penelitian}

PT. Optima Media Sinergi yang beralamat di Jl. Aria Putra, No.67, Serua Indah, Ciputat, Kota Tangerang Selatan, Banten. Komisaris perusahaan tersebut ialah I Putu Ananta Wiryamita dan Direktur Perusahaan bernama Rachmat Subakti. Perusahaan ini bergerak di bidang Digital Media Buying, Web Development, Digital Asset Management dan Promotor. PT. Optima Media Sinergi telah dilengkapi legalitas Akte Pendirian No. 20 Tanggal 22 Januari 2016,Notaris / PPAT Rifqi Baisa S.H., M.Kn., Akte Perubahan No. 2 Tanggal 10 Februari 2017, Notaris / PPAT Rifqi Baisa S.H., M.Kn. Adapun Surat Izin Usaha Perdagangan (SIUP) Menengah No: 881/24.1PM.7/31.71/-1.824.27/e/2017 dan Tanda Daftar Perusahan (TDP) PT No: 09.05.1.73.88674. 


\section{B. Uji Instrumen}

1. Uji Validitas

Dalam uji validitas menggunakan perhitungan statistik dengan software SPSS Version 22.00 for windows. Butir pernyataan dikatakan valid, jika nilai $\mathrm{r}$ hitung $>\mathrm{r}$ tabel.

Tabel 4.1

Hasil Uji Validitas Budaya organisasi (X1)

\begin{tabular}{|c|c|c|c|c|}
\hline Variabel & Butir pernyataan & r hitung & $\mathrm{r}$ tabel & Keterangan \\
\hline \multirow{15}{*}{$\begin{array}{l}\text { Budaya } \\
\text { Organisasi } \\
\text { (X1) }\end{array}$} & 1 & 0,588 & 0,273 & Valid \\
\hline & 2 & 0,469 & 0,273 & Valid \\
\hline & 3 & 0,634 & 0,273 & Valid \\
\hline & 4 & 0,668 & 0,273 & Valid \\
\hline & 5 & 0,424 & 0,273 & Valid \\
\hline & 6 & 0,557 & 0,273 & Valid \\
\hline & 7 & 0,608 & 0,273 & Valid \\
\hline & 8 & 0,617 & 0,273 & Valid \\
\hline & 9 & 0,519 & 0,273 & Valid \\
\hline & 10 & 0,522 & 0,273 & Valid \\
\hline & 11 & 0,572 & 0,273 & Valid \\
\hline & 12 & 0,688 & 0,273 & Valid \\
\hline & 13 & 0,569 & 0,273 & Valid \\
\hline & 14 & 0,648 & 0,273 & Valid \\
\hline & 15 & 0,409 & 0,273 & Valid \\
\hline
\end{tabular}

Setelah dilakukan uji validitas terhadap variabel budaya organisasi maka $r$ hitung memilki nilai lebih besar dari $r$ tabel yaitu 0,273 sehingga dinyatakan valid.

Tabel 4.2

Hasil Uji Validitas Variabel Insentif (X2)

\begin{tabular}{|c|c|c|c|c|}
\hline Variabel & Butir pernyataan & r hitung & r tabel & Keterangan \\
\hline \multirow{7}{*}{} & 1 & 0,600 & 0,273 & Valid \\
\cline { 2 - 5 } & 2 & 0,578 & 0,273 & Valid \\
\cline { 2 - 5 } & 3 & 0,554 & 0,273 & Valid \\
\cline { 2 - 5 } & 4 & 0,697 & 0,273 & Valid \\
\cline { 2 - 5 } Insentif & 5 & 0,688 & 0,273 & Valid \\
\cline { 2 - 5 } & 6 & 0,395 & 0,273 & Valid \\
\cline { 2 - 5 } & 7 & 0,676 & 0,273 & Valid \\
\cline { 2 - 5 } & 8 & 0,583 & 0,273 & Valid \\
\cline { 2 - 5 } & 9 & 0,566 & 0,273 & Valid \\
\cline { 2 - 5 } & 10 & 0,625 & 0,273 & Valid \\
\cline { 2 - 5 } & 11 & 0,334 & 0,273 & Valid \\
\cline { 2 - 5 } & 12 & 0,319 & 0,273 & Valid \\
\cline { 2 - 5 } & 13 & 0,328 & 0,273 & Valid \\
\cline { 2 - 5 } & 14 & 0,296 & 0,273 & Valid \\
\hline
\end{tabular}

Setelah dilakukan uji validitas terhadap variabel insentif maka $r$ hitung memilki nilai lebih besar dari $r$ tabel yaitu 0,273 sehingga dinyatakan valid. 
Tabel 4.3

Hasil Uji Validitas Variabel Motivasi Kerja (Y)

\begin{tabular}{|c|c|c|c|c|}
\hline Variabel & Butir pernyataan & r hitung & r tabel & Keterangan \\
\hline \multirow{7}{*}{} & 1 & 0,493 & 0,273 & Valid \\
\cline { 2 - 5 } & 2 & 0,810 & 0,273 & Valid \\
\cline { 2 - 5 } & 3 & 0,441 & 0,273 & Valid \\
\cline { 2 - 5 } & 4 & 0,630 & 0,273 & Valid \\
\cline { 2 - 5 } & 5 & 0,525 & 0,273 & Valid \\
\cline { 2 - 5 } Kotivasi & 6 & 0,820 & 0,273 & Valid \\
\cline { 2 - 5 } & 7 & 0,510 & 0,273 & Valid \\
\cline { 2 - 5 } & 8 & 0,618 & 0,273 & Valid \\
\cline { 2 - 5 } & 9 & 0,561 & 0,273 & Valid \\
\cline { 2 - 5 } & 10 & 0,586 & 0,273 & Valid \\
\cline { 2 - 5 } & 11 & 0,552 & 0,273 & Valid \\
\cline { 2 - 5 } & 12 & 0,654 & 0,273 & Valid \\
\cline { 2 - 5 } & 14 & 0,869 & 0,273 & Valid \\
\cline { 2 - 5 } & 15 & 0,748 & 0,273 & Valid \\
\hline
\end{tabular}

Setelah dilakukan uji validitas terhadap variabel motivasi kerja maka $r$ hitung memilki nilai lebih besar dari $r$ tabel yaitu 0,273 sehingga dinyatakan valid.

Tabel 4.4

Hasil Uji Validitas Variabel Produktivitas Karyawan (Z)

\begin{tabular}{|c|c|c|c|c|}
\hline Variabel & Butir pernyataan & r hitung & r tabel & Keterangan \\
\hline & 1 & 0,663 & 0,273 & Valid \\
\cline { 2 - 5 } & 2 & 0,571 & 0,273 & Valid \\
\cline { 2 - 5 } & 3 & 0,646 & 0,273 & Valid \\
\cline { 2 - 5 } & 4 & 0,752 & 0,273 & Valid \\
\cline { 2 - 5 } & 5 & 0,628 & 0,273 & Valid \\
\cline { 2 - 5 } Karyawan (Z) & 6 & 0,499 & 0,273 & Valid \\
\cline { 2 - 5 } & 7 & 0,459 & 0,273 & Valid \\
\cline { 2 - 5 } & 8 & 0,501 & 0,273 & Valid \\
\cline { 2 - 5 } & 10 & 0,608 & 0,273 & Valid \\
\cline { 2 - 5 } & 11 & 0,519 & 0,273 & Valid \\
\cline { 2 - 5 } & 12 & 0,397 & 0,273 & Valid \\
\cline { 2 - 5 } & 13 & 0,504 & 0,273 & Valid \\
\cline { 2 - 5 } & 14 & 0,423 & 0,273 & Valid \\
\cline { 2 - 5 } & 15 & 0,650 & 0,273 & Valid \\
\hline
\end{tabular}

Setelah dilakukan uji validitas terhadap variabel produktivitas karyawan maka $r$ hitung memilki nilai lebih besar dari $r$ tabel yaitu 0,273 sehingga dinyatakan valid.

\section{Uji Reliabilitas}

a. Uji Reliabilitas X1 (Budaya Organisasi)

Setelah dipastikan semua pernyataan valid maka uji selanjutnya adalah uji kuesioner. Uji reliabilitas menggunakan rumus alpha cronbach dengan SPSS. Dari hasil perhitungan menggunakan Software IBM SPSS 22 hasil lengkap dapat dilihat pada tabel berikut : 


\section{Tabel 4.5}

Hasil pengujian perhitungan reliabilitas variabel X1

Reliability Statistics

Nilai $r_{c a}$ variabel $X 1,0,848$, nilainya lebih besar dari 0,6. Dengan demikian instrumen kuesioner indikator variabel X1 dinyatakan reliabel.

b. Uji Reliabilitas X2 (Insentif)

Tabel 4.6

Hasil pengujian perhitungan reliabilitas variabel X2

Reliability Statistics

\begin{tabular}{|l|l|}
\hline Cronbach's Alpha & $\mathrm{N}$ of Items \\
\hline
\end{tabular}

\begin{tabular}{r|r|}
\hline, 804 & 15 \\
\hline
\end{tabular}

Nilai $r_{c a}$ variabel X2 dapat dilihat bernilai 0,804 , nilainya lebih besar dari 0,6 . Dengan demikian kuesioner indikator variabel X2 dinyatakan reliabel

c. Uji Reliabilitas Y (Motivasi kerja)

\section{Tabel 4.7}

Hasil pengujian perhitungan reliabilitas variabel Y

Reliability Statistics

\begin{tabular}{|l|l|}
\hline Cronbach's Alpha & $\mathrm{N}$ of Items \\
\hline
\end{tabular}

Nilai $r_{c a}$ variabel $Y$ dapat dilihat bernilai 0,889 , nilainya lebih besar dari 0,6. Dengan demikian kuesioner indikator variabel Y dinyatakan reliabel

d. Uji Reliabilitas Z (Produktivitas Karyawan)

\section{Tabel 4.8}

Hasil pengujian perhitungan reliabilitas variabel $\mathrm{Z}$

Reliability Statistics

\begin{tabular}{|l|l|}
\hline Cronbach's Alpha & $\mathrm{N}$ of Items \\
\hline
\end{tabular}

,847

Nilai $r_{c a}$ variabel $Z$ dapat dilihat bernilai 0,847 , nilainya lebih besar dari 0,6 . Dengan demikian kuesioner indikator variabel $\mathrm{Z}$ dinyatakan reliabel

\section{Persamaan Regresi Linier Berganda}

Adapun hasil perhitungan persamaan regresi linier berganda dengan menggunakan perhitungan software SPSS 22 dapat dilihat pada tabel berikut:

\section{Tabel 4.9}

\section{Hasil Analisis Regresi Linear Berganda X1 dan X2 terhadap Y}

Coefficients $^{\mathrm{a}}$

\begin{tabular}{|c|c|c|c|c|c|}
\hline \multirow[b]{2}{*}{ Model } & \multicolumn{2}{|c|}{ Unstandardized Coefficients } & \multirow{2}{*}{$\begin{array}{c}\text { Standardized } \\
\text { Coefficients } \\
\text { Beta }\end{array}$} & \multirow[b]{2}{*}{$t$} & \multirow[b]{2}{*}{ Sig. } \\
\hline & $\mathrm{B}$ & Std. Error & & & \\
\hline $1 \quad$ (Constant) & 12,931 & 10,707 & & 1,208 & ,233 \\
\hline Budaya Organisasi (X1) & ,459 & 181 & ,391 & 2,539 & ,014 \\
\hline Insentif (X2) & ,280 & ,212 & 204 & 1,324 & ,192 \\
\hline
\end{tabular}

a. Dependent Variable: Motivasi Kerja (Y)

Berdasarkan tabel diatas dapat ditarik kesimpulan bahwa persamaan regresi linier berganda yang terbentuk $\mathrm{Y}=12,931+0,459 \mathrm{X}_{1}+0,280 \mathrm{X}_{2}$. 


\section{Korelasi Berganda dan Koefisien Determinasi}

Berdasarkan tabel 4.10, dapat dilihat nilai korelasi berganda sebesar $r=0,543$ yang berarti hubungan antara budaya organisasi dan insentif terhadap motivasi kerja karyawan pada PT Optima Media Sinergi berada pada kategori sedang.

\section{Tabel 4.10}

Hasil Uji Korelasi Berganda dan Koefisien Determinasi X1 dan X2 terhadap Y

Model Summaryb

\begin{tabular}{|c|c|c|c|c|c|c|c|c|c|}
\hline \multirow[b]{2}{*}{ Model } & \multirow[b]{2}{*}{$\mathrm{R}$} & \multirow[b]{2}{*}{$\begin{array}{c}\mathrm{R} \\
\text { Square }\end{array}$} & \multirow[b]{2}{*}{$\begin{array}{c}\text { Adjusted } \\
\text { R } \\
\text { Square }\end{array}$} & \multirow{2}{*}{$\begin{array}{c}\text { Std. } \\
\text { Error of } \\
\text { the } \\
\text { Estimate }\end{array}$} & \multicolumn{5}{|c|}{ Change Statistics } \\
\hline & & & & & $\begin{array}{c}\mathrm{R} \\
\text { Square } \\
\text { Change }\end{array}$ & $\begin{array}{c}F \\
\text { Change }\end{array}$ & df1 & df2 & $\begin{array}{c}\text { Sig. F } \\
\text { Change }\end{array}$ \\
\hline 1 &, $543^{a}$ & 0,295 & 0,266 & 5,7582 & 0,295 & 10,254 & 2 & 49 & ,000 \\
\hline
\end{tabular}

a. Predictors: (Constant), Insentif (X2), Budaya Organisasi (X1)

b. Dependent Variable: Motivasi Kerja (Y)

Nilai koefisien determinasi (KD) tersebut diperoleh sebesar 29,50\%. Hal ini menunjukan bahwa besarnya kontribusi variabel budaya organisasi dan insentif terhadap motivasi kerja karyawan sebesar $29,50 \%$, sedangkan selebihnya sebesar $70.50 \%$ dipengaruhi faktor-faktor lain yang tidak dibahas dalam penelitian ini.

Tabel 4.11

\section{Hasil Uji Korelasi Sederhana dan Koefisien Determinasi Variabel Y terhadap Z}

Model Summaryb

\begin{tabular}{|c|c|c|c|c|c|c|c|c|c|}
\hline \multirow[b]{2}{*}{ Model } & \multirow[b]{2}{*}{$\mathrm{R}$} & \multirow[b]{2}{*}{$\begin{array}{c}\mathrm{R} \\
\text { Square }\end{array}$} & \multirow[b]{2}{*}{$\begin{array}{c}\text { Adjusted } \\
\text { R } \\
\text { Square }\end{array}$} & \multirow{2}{*}{$\begin{array}{c}\text { Std. } \\
\text { Error of } \\
\text { the } \\
\text { Estimate }\end{array}$} & \multicolumn{5}{|c|}{ Change Statistics } \\
\hline & & & & & $\begin{array}{c}\mathrm{R} \\
\text { Square } \\
\text { Change }\end{array}$ & $\begin{array}{c}F \\
\text { Change }\end{array}$ & df1 & df2 & $\begin{array}{c}\text { Sig. F } \\
\text { Change }\end{array}$ \\
\hline 1 & $.564^{a}$ & 318 & 304 & 4,4783 & 318 & 23,270 & 1 & 50 & .000 \\
\hline
\end{tabular}

a. Predictors: (Constant), Motivasi Kerja (Y)

b. Dependent Variable: Produktivitas Karyawan $(Z)$

Berdasarkan tabel 4.11, dapat dilihat nilai korelasi sederhana sebesar $r=0,564$ yang berarti hubungan antara motivasi kerja terhadap produktivitas karyawan pada PT Optima Media Sinergi berada pada kategori sedang.

Adapun nilai koefisien determinasi (KD) tersebut diperoleh sebesar 31,80\%. Hal ini menunjukan bahwa besarnya kontribusi variabel antara motivasi kerja terhadap produktivitas karyawan sebesar $31,80 \%$, sedangkan selebihnya sebesar 68,20\% dipengaruhi faktor-faktor lain yang tidak dibahas dalam penelitian ini.

\section{Uji Hipotesis}

\section{a. Uji T}

\section{1) Budaya Organisasi $\left(X_{1}\right)$ terhadap Motivasi Kerja (Y)}

Berdasarkan tabel 4.9 di atas dapat dilihat bahwa variabel Budaya organisasi $\left(\mathrm{x}_{1}\right)$ diperoleh signifikansi t lebih kecil dari $0,05(0,014<0,05)$ dan $\mathrm{t}_{\text {hitung }} 2,539>$ $\mathrm{t}$ tabel sebesar 2,009 $(2,539>2,009)$ atau berarti $\mathrm{H}_{01}$ ditolak dan $\mathrm{H}_{\mathrm{a} 1}$ diterima, hal ini menunjukan bahwa terdapat pengaruh yang signifikan antara Budaya organisasi $\left(\mathrm{x}_{1}\right)$ terhadap Motivasi Kerja $(\mathrm{y})$. 


\section{2) Insentif $\left(\mathrm{X}_{2}\right)$ terhadap Motivasi Kerja (Y)}

Berdasarkan tabel 4.9 diatas dapat dilihat bahwa variabel Insentif (x2) diperoleh signifikansi $\mathrm{t}$ lebih besar dari 0,05 $(0,192>0,05)$ dan $\mathrm{t}$ hitung 1,324 $<\mathrm{t}$ tabel sebesar 2,009 $(1,324<2,009)$ atau berarti $\mathrm{H}_{02}$ diterima dan $\mathrm{H}_{\mathrm{a} 2}$ ditolak, hal ini menunjukan bahwa tidak terdapat pengaruh yang signifikan antara Insentif $\left(\mathrm{x}_{2}\right)$ terhadap Motivasi Kerja (y).

Tabel 4.12

Hasil Uji T (Variabel Y terhadap Z)

Coefficients ${ }^{\text {a }}$

\begin{tabular}{|c|c|c|c|c|c|}
\hline \multirow[b]{2}{*}{ Model } & \multicolumn{2}{|c|}{$\begin{array}{c}\text { Unstandardized } \\
\text { Coefficients }\end{array}$} & \multirow{2}{*}{$\begin{array}{c}\text { Standardized } \\
\text { Coefficients }\end{array}$} & \multirow[b]{2}{*}{$l$} & \multirow[b]{2}{*}{ Sig. } \\
\hline & $\mathrm{B}$ & Std. Error & & & \\
\hline 1 (Constant) & 33,372 & 5,519 & & 6,047 &, 000 \\
\hline $\begin{array}{l}\text { Motivasi Kerja } \\
\text { (Y) }\end{array}$ &, 450 & ,093 &, 564 & 4,824 &, 000 \\
\hline
\end{tabular}

a. Dependent Variable: Produktivitas Karyawan $(\mathrm{Z})$

\section{3) Motivasi Kerja (Y) terhadap Produktivitas Karyawan (Z)}

Berdasarkan tabel diatas dapat dilihat bahwa variabel Motivasi Kerja (Y) diperoleh signifikansi t lebih kecil dari $0,05(0,000<0,05)$ dan $\mathrm{t}_{\text {hitung }} 6,824>\mathrm{t}_{\text {tabel }}$ sebesar 2,009 $(6,824>2,009)$ atau berarti $\mathrm{H}_{02}$ ditolak dan $\mathrm{H}_{\mathrm{a} 2}$ diterima, hal ini menunjukan bahwa terdapat pengaruh yang signifikan antara Motivasi Kerja (Y) terhadap Produktivitas Karyawan (Z)

\section{b. Uji F}

Untuk menguji pengaruh Budaya Organisasi $\left(\mathrm{x}_{1}\right)$ dan Insentif $\left(\mathrm{x}_{2}\right)$ secara bersama-sama terhadap Motivasi Kerja (y), dapat digunakan uji statistik F (uji F), dengan menggunakan taraf signifikansi 5\% $(0,05)$.

Tabel 4.13

Hasil Uji F (X1 dan X2 terhadap Y)

ANOVA ${ }^{\mathrm{a}}$

\begin{tabular}{|ll|r|r|r|r|r|}
\hline \multicolumn{2}{|c|}{ Model } & \multicolumn{1}{|c|}{$\begin{array}{c}\text { Sum of } \\
\text { Squares }\end{array}$} & df & Mean Square & F & Sig. \\
\hline 1 & Regression & 679,969 & 2 & 339,985 & 10,254 &, $000^{\mathrm{b}}$ \\
& Residual & 1624,704 & 49 & 33,157 & & \\
& Total & 2304,673 & 51 & & & \\
\hline
\end{tabular}

a. Dependent Variable: Motivasi Kerja (Y)

b. Predictors: (Constant), Insentif (X2), Budaya Organisasi (X1)

Dari hasil uji $\mathrm{F}$ dapat diperoleh nilai $\mathrm{f}_{\text {hitung }}>\mathrm{f}_{\text {tabel }}$ yaitu 10,254 $>3,18$ dan nilai sig $<0,05$ atau $0,000<0,005$ "Maka, Budaya Organisasi $\left(\mathrm{x}_{1}\right)$ dan Insentif $\left(\mathrm{x}_{2}\right)$ memiliki pengaruh yang signifikan terhadap Motivasi Kerja (y)"

\section{PENUTUP}

\section{A. Kesimpulan}

Dari hasil penelitian dapat ditarik beberapa kesimpulan yaitu:

1. Budaya organisasi $\left(\mathrm{x}_{1}\right)$ diperoleh signifikansi $\mathrm{t}$ lebih kecil dari $0,05(0,014<0,05)$ dan $\mathrm{t}$ hitung 2,539 $>\mathrm{t}_{\text {tabel }}$ sebesar 2,009 $(2,539>2,009)$ atau berarti $\mathrm{H}_{01}$ ditolak dan $\mathrm{H}_{\mathrm{a} 1}$ diterima, 
hal ini menunjukan bahwa terdapat pengaruh yang signifikan antara Budaya organisasi $\left(\mathrm{x}_{1}\right)$ terhadap Motivasi Kerja (y).

2. Insentif (x2) diperoleh signifikansi t lebih besar dari 0,05 (0,192>0,05) dan $\mathrm{t}_{\text {hitung }} 1,324$ $<\mathrm{t}_{\text {tabel }}$ sebesar 2,009 $(1,324<2,009)$ atau berarti $\mathrm{H}_{02}$ diterima dan $\mathrm{H}_{\mathrm{a} 2}$ ditolak, hal ini menunjukan bahwa tidak terdapat pengaruh yang signifikan antara Insentif $\left(\mathrm{x}_{2}\right)$ terhadap Motivasi Kerja (y).

3. Hasil uji $\mathrm{F}$ dapat diperoleh nilai $\mathrm{f}_{\text {hitung }}>\mathrm{f}_{\text {tabel }}$ yaitu $10,254>3,18$ dan nilai sig $<0,05$ atau $0,000<0,005$ "Maka, Budaya Organisasi $\left(\mathrm{x}_{1}\right)$ dan Insentif $\left(\mathrm{x}_{2}\right)$ memiliki pengaruh yang signifikan terhadap Motivasi Kerja (y)".

4. Motivasi Kerja (Y) diperoleh signifikansi t lebih kecil dari $0,05(0,000<0,05)$ dan $\mathrm{t}_{\text {hitung }}$ $6,824>\mathrm{t}_{\text {tabel }}$ sebesar 2,009 $(6,824>2,009)$ atau berarti $\mathrm{H}_{02}$ ditolak dan $\mathrm{H}_{\mathrm{a} 2}$ diterima, hal ini menunjukan bahwa terdapat pengaruh yang signifikan antara Motivasi Kerja (Y) terhadap Produktivitas Karyawan (Z)

\section{B. Saran}

Saran dalam penelitian ini, yaitu :

1. Disarankan agar budaya organisasi di PT Optima Media Sinergi dapat diperhatikan lebih baik lagi agar terciptanya budaya organisasi yang nyaman dan aman dalam bekerja sehingga dapat memotivasi kerja karyawan menjadi lebih baik lagi.

2. Disarankan agar insentif diperhatikan oleh para pimpinan di PT Optima Media Sinergi, agar karyawan pada perusahaan ini dapat termotivasi bekerja lebih profesional dan terampil dalam bekerja.

3. Disarankan juga untuk perusahaan agar budaya organiasi dan insentif secara bersamasama diperhatikan agar terciptanya perusahaan yang mampu bersaing dikarenakan para karyawannya termotivasi dalam bekerja.

4. Dan disarankan juga agar motivasi kerja terus dipantau oleh para pimpinan di PT Optima Media Sinergi, agar produktivitas karyawan pada perusahaan ini semakin meningkat guna kemajuan perusahaan. Dan Bagi peneliti selanjutnya, agar dapat menambah variabel lain dan tidak hanya terbatas pada variabel budaya organisasi, insentif, motivasi kerja dan produktivitas karyawan.

\section{DAFTAR PUSTAKA}

Arep, Ishak dan Hendri Tanjung. 2003. “Manajemen Sumber Daya Manusia”. Jakarta: Universitas Trisakti.

Arikunto, Suharsimi. 2002, “Prosedur Penelitian”, Edisi Revisi V, Jakarta : Rineka Cipta.

Duwi Puritno.2013 “Analisis Korelasi, Regresi Dan Multivariate Dengan SPSS”. Yogyakarta: Gava Media.

Edy Sutrisno, 2011, “Manajemen Sumber Daya Manusia”, Jakarta: Kencana.

Ghozali , 2002. "Metode Penelitian", Jakarta : Penerbit Guna Dharma.

Hasibuan, Malayu. 2009, "Manajemen Sumberdaya Manusia”. PT. Bumi Aksara, Jakarta

Riduwan, 2009. "Metode Dan Teknik Menyusun Proposal Penelitian”, Bandung: Penerbit Alfabeta.

Saryono, 2010. "Metode Penelitian Kualitatif," PT. Alfabeta, Bandung

Subkhi, Akhmad dan Mohammad Jauhar, 2013. "Pengantar Teori dan Perilaku Organisasi", PT. Prestasi Pustakaraya, Jakarta,

Sugiyono, 2011. "Metode penelitian kuntitatif kualitatif dan R\&D”. Alfabeta, Bandung,

Terhadap Kinerja Karyawan Pada Bank BTN Kantor Cabang Tangerang. Jurnal Semarak, 2(1). Sunjoyo dkk., 2013, “Aplikasi SPSS untuk SMART Riset, Alfabeta,” Bandung 
Supranto. J. 2009. “Statistik Teori dan Aplikasi,” Edisi Ketujuh. Erlangga, Jakarta, Sutrisno, Edy. 2009. "Manajemen Sumber Daya Manusia”. Jakarta: Kencana Suwatno. 2001. "Asas-Asas Manajemen Sumber Daya Manusia", Bandung: Suci Press Tika, Moh. Pabunda, 2012, "Budaya Organisasi dan Peningkatan Kinerja Perusahaan”, PT. Bumi Aksara, Jakarta.

Tjutju Yuniarsih dan Suwanto, 2009 "Manajemen Sumber Daya Manusia”. Bandung : Alfabeta

Tri, Heru, Al Fajar dan Siti. 2010. “Manajemen Sumberdaya Manusia”. Yogyakarta : Sekolah Tinggi Ilmu Manajemen YKPN

Veithzal, Rivai. 2006. “Manajemen Sumber Daya Manusia”. Jakarta: PT. Raja Grafindo Persada 